\title{
Association of a polymorphism in SREBP1 with fatty acid composition and lipogenic gene expression in beef cattle breeds
}

\section{David Gamarra}

Universidad del Pais Vasco

Noelia Aldai

Universidad del Pais Vasco

Aisaku Arakawa

NARO Institute of Livestock and Grassland Science

Marian M. de Pancorbo

Universidad del Pais Vasco

Masaaki Taniguchi ( $\square$ masaakit@affrc.go.jp )

NARO Institute of Livestock and Grassland Science https://orcid.org/0000-0001-8194-3577

Research article

Keywords: backfat, beef cattle, desaturation, fatty acids, gene expression, indel, sterol regulatory elementbinding protein

Posted Date: September 26th, 2019

DOI: https://doi.org/10.21203/rs.2.15242/v1

License: (9) (1) This work is licensed under a Creative Commons Attribution 4.0 International License. Read Full License 


\section{Abstract}

Background Sterol regulatory element-binding protein 1 (SREBP1) plays an important role in the lipogenesis and fatty acid (FA) composition in fat cells and is consequently considered to influence the nutritional quality of beef. SREBP1 regulates lipogenic gene transcription including stearoyl-CoA desaturases (SCDs) that are responsible for unsaturation of FAs. Therefore, we performed phylogenetic analysis on SREBP1 gene sequences, including $84 \mathrm{bp}$-indel, among mammals to elucidate the evolutionary importance of this polymorphism and possible effect in the FA composition. Additionally, we analyzed the association between the indel, FA composition, and gene expression of SREBP1 and SCDs in backfat of several commercial type beef breeds in northern Spain (Pirenaica, Salers and HolsteinFriesian).

Results In ruminants, the indel region was relatively highly conserved in comparison with the rest of intron 5 sequence or mRNA of SREBP1, suggesting the potential functionality throughout evolution. We applied the definition of the insertion and deletion of 84 bp in intron 5: S (Short) and L (Long) alleles, respectively. Then, we figured the indel is associated with saturated FA (SFA) and several polyunsaturated FA (PUFA) depending on commercial type, specifically Pirenaica bulls, whose SS/SL genotype has been associated with a higher content of 18:0, n-3 and 18:3n-3 $(p<0.05)$. In Salers, $S$ allele showed the highest frequency (0.385) among all breeds, while SS genotype had high positive correlations between SREBP1 gene expression and UFA contents. Significant correlations between SCD1 and SFAs (16:0) in SL genotype of Pirenaica bulls, but also 9c-16:1 in Pirenaica breed $(p<0.05)$, suggests a differential relationship between SCD1 and 16:0/9c-16:1 FA contents depending on the indel genotype in this breed. Overall, SS and SS/SL genotypes had a positive correlation between SCD5 and 18:0 $(p<0.05)$ and a negative correlation between SCD5 and 9c-18:1 ( $p>0.05)$.

Conclusions These results suggest that the indel is associated with SFA and PUFA content depending on commercial type. Moreover, the correlations between lipogenic genes (SREBP1 and SCDs) with 16:0 and $9 c-16: 1$, but also $18: 0$ and $9 c-18: 1$, seems to be attributed to the indel genotype. These findings are useful for beef/dairy breeding to supply nutritionally favorable products.

\section{Background}

It is widely recognized the beneficial effects of unsaturated fatty acids (UFA) in human health, which has been also emphasized by the World Health Organization [1, 2]. Thus, enhancing the UFA profile in animalderived products improves the nutritional quality of them [3]. In terms of polyunsaturated fatty acids (PUFA), $n-3$ and $n-6$ are the most common, being linoleic (LA; $18: 2 n-6)$ and a-linolenic (ALA; 18:3n-3) acids the most abundant ones. Due to the inability of humans to synthesize these fatty acids (FA), they are considered essential dietary FAs. Lipogenesis is nutritionally controlled at the transcriptional level by a common family of transcription factors designated sterol regulatory element binding proteins (SREBP) [4]. These transcription factors have an important role in controlling around 30 genes affecting the 
synthesis of FAs, triacylglycerols, and glycerophospholipids [5], and are considered also master regulators of cholesterogenesis [6].

There are 3 major SREBP isoforms named SREBP1a, SREBP1C, and SREBP2 identified in humans and rodents as well as cattle $[7,8]$. Over time, SREBPs have been conserved from fungi to mammals, and the phylogenetic analysis demonstrated the existence of predicted SREBP homologs across Eukarya [9]. Moreover, regulation and functions of these transcription factors and their implication in several pathologies $[10,11]$ and also their association with nutritionally healthy FA profiles in milk and meat $[12$, 13] are of permanent interest.

SREBPs regulate gene transcription activation by binding to the sterol regulatory element (SRE) sequences present in the promoter of downstream genes, including stearoyl-CoA desaturase (SCD) genes [14]. Therefore, differences in expression level and polymorphisms of SREBP gene may affect the expression of other downstream genes, leading to differences in FA composition of adipose tissues. In this regard, several studies have reported the association of genetic polymorphisms within SREBP genes with FA composition in cattle $[15,16]$, whereas mRNA expression of SREBP1 was recently elucidated to correlate with differences in FA profile of several cattle breeds [17].

In relation to polymorphisms, Hoashi et al. [15] identified an interesting 84 bp insertion/deletion polymorphism (84 bp-indel; rs133958066) in chromosome 19 of intron 5 of SREBP1, which was associated with higher monounsaturated FA (MUFA) content and lower melting point of intramuscular fat. This polymorphism has been widely investigated in cattle breeds such as Holstein-Friesian, Hereford and Angus, as well as in Bos indicus and other endogenous breeds $[18,19,20]$. The 84 bp-indel has also been associated with growth traits [21] and milk production [22], while some other studies have investigated its association with FA composition of backfat and muscle [23, 24, 25, 26, 27]. However, there are no studies investigating the potential effect of $84 \mathrm{bp}$-indel along with SREBP1 gene expression and their association with the FA profile. Therefore, the objective of the present study was to characterize the $84 \mathrm{bp}$-indel polymorphism of SREBP1 gene in several commercial cattle breeds produced in northern Spain (Pirenaica, Salers, and Holstein-Friesian) and to evaluate the association between the indel and the FA profile of backfat considering the gene expression of SREBP1 and downstream SCD gene isoforms.

\section{Result}

\section{Evaluation of SREBP1 genotyping data}

Detecting the SSLP of bovine SREBP1, two alleles (S, 698 bp band; L, 782 bp band) and 3 genotypes (SS, $S L$ and $L L$ ) were identified in cattle commercialized in the Basque region (Figure 1a). Then, melting profiles of each genotype were grouped into distinct clusters which were assigned as reference clusters (Figure 1b). All samples from the same genotype were grouped in the same cluster with confidence levels over $98 \%$; melting temperatures were stable and low standard deviations for each genotype were observed. 


\section{SREBP1 alignment among mammals}

The bovine sequence of SREBP1 mRNA demonstrated high homology with the sequence of other ruminants such as zebu (Bos indicus, 99\%), goat (Capra hircus, 96\%), sheep (Ovis aries, 93\%), and buffalo (Bubalus bubalis, 85\%) (Figure 2a). Likewise, it showed a moderate to high homology when compared with other mammals such as pig (Sus scrofa, 82\%), dog (Canis familiaris, 82\%), horse (Equus caballus, 73\%), rat (Rattus norvegicus, 73\%), and mouse (Mus musculus, 72\%). Furthermore, bovine SREBP1 mRNA sequence showed higher homology to SREBP1C isoform of hominids such as human (Homo sapiens) or chimpanzee (Pan troglodytes) (82 \%) (Figure 2a) than to SREBP1a (65\%) of the same hominids. In general, high bootstraps (of 100) were observed in the tree nodes among ruminants, but also pig, demonstrating the strength of these alignments. Node bootstraps were lower for horse, dog and hominids since these mammals phylogenetically belong to different animal families. SREBP1 full gene alignment showed higher similarity among mammals in exon regions, and interestingly, the intron 5 showed higher similarity than other introns (intron 1, 2, 6, 9,11, 12 and 18; Figure 2b). The proportion of homology in SREBP1 gene showed smaller similarity among cattle and several ruminants such as buffalo and goat (<80\%), whereas in non-ruminant mammals, the full gene had smaller similarity in comparison with mRNA of SREBP1. Alignment of intron 5 from bovine SREBP1 and other mammals showed that homology is higher in ruminants (99-96\%) compared with non-ruminant mammals (71-45 $\%$; Figure $2 \mathrm{~b}$ ). Interestingly, alignment of bovine $84 \mathrm{bp}$-indel region showed the highest homology among ruminants ( $\geq 99 \%$ ), and homology was lower in other mammals (76-56\%). In general, the 84 bp-indel region is highly conserved among mammals even this polymorphism is located in a non-coding region. However, $\mathrm{S}$ allele was not observed in any of the intron sequences reported in Genbank for the compared species. Larger gaps were due to sequence differences among mammals, for example as observed in horse (Equus caballus)..

\section{Allele frequencies and associations with the fatty acid composition}

The genotype and allele frequencies of the $84 \mathrm{bp}$-indel of bovine SREBP1 gene determined in commercial types are reported in Table 1. In SS genotype, the observed heterozygosity was higher than that of the expected, whereas Hardy-Weinberg equilibrium test showed no significant differences between observed and expected genotypes in Salers and Pirenaica animals. The frequency of the minor allele (S) was higher in Salers bulls (0.385) compared to Pirenaica heifers (0.214) and bulls (0.135). In contrast, Holstein-Friesian cows did not show 84 bp deletion (S allele) and all samples presented the LL genotype.

When association analyses were performed (Table 2), overall, very few differences were observed between genotypes within each of the bovine commercial types studied. No differences were observed in Salers bulls and Pirenaica heifer, while several differences between genotypes (SS/SL vs LL) were found in Pirenaica bulls. Higher 18:0, 18:3n-3 and total $n-3$ contents were observed in SS/SL compared to LL 
genotype $(p<0.05)$. It was also observed that Pirenaica bulls and heifers showed higher PUFA content, including $n-6,18: 2 n-6, n-3$ and $18: 3 n-3$, in SS/SL individuals compared to LL individuals $(p>0.05)$, while this was opposite in Salers bulls $(p>0.05)$.

Correlations among bovine SREBP1 gene expression and contents of major individual and groups of FA of each genotype (84 bp-indel) and commercial type were performed in order to elucidate the effect of SREBP1 gene on the backfat FA composition in beef cattle (Figure 3). Overall, few significant correlations were observed between gene expression and individual and groups of FA, and most of them were found in Holstein-Friesian cows (LL genotype). In this commercial type, positive and significant correlations were found among individual (9c-16:1, 9c-18:1) and total MUFA, and 16:0 contents and SREBP1 gene expression ( $p \leq 0.05)$. Overall, Salers bulls showed positive correlations among SREBP1 gene expression and UFAs in SS, SL and LL with highest values in SS genotype $(p>0.05)$, whereas, the correlations were negative for SFAs. In Pirenaica heifer individuals of SS genotype, high and negative correlations among FAs and gene expression were observed compared to individuals of SL, SS/SL and LL genotypes. However, significant values were only observed for $9 c-18: 1$ in individuals of SL genotype $(P \leq 0.05)$.

When Pirenaica breed (both bulls and heifers) was considered, individuals of SS genotype showed negative correlations among gene expression and MUFAs whereas correlations were positive with PUFAs $(p>0.05)$. When all individuals except Holstein-Friesians (only LL genotype) were considered $(\mathrm{n}=78)$, in general, individuals of SS genotype showed negative correlations with SFA and MUFA, and positive correlation with PUFA $(p>0.05)$, while these correlations were opposite in SL and LL genotypes especially for PUFA $(p>0.05)$.

Partial correlations among SCD1 and SCD5 gene expressions and FA composition (individual and groups) have been depicted in a heatmap (Figure 4) for each of the genotype (84 bp-indel; SS, SL, SS/SL, LL) and commercial type in order to evaluate the effect of the presence/absence of the $84 \mathrm{bp}$-indel sequence on the downstream genes. In general terms, quite opposite correlations were evident when comparing SCD1 and $S C D 5$ gene expression correlations with FAs (individual and groups). Regarding $S C D 1$, in Salers bulls most of the significant $(p \leq 0.05)$ and positive correlations were observed in SS genotype and PUFAs, while correlations were negative $(p \leq 0.05)$ in LL genotype and SFAs and PUFAs. In Pirenaica bulls, both SL and LL genotype showed significant and positive correlations with $16: 0$ and SFAs, while negative ( $p \leq$ 0.05) correlation were observed for SCD5 for the same FAs showing contrast pattern between both isoforms. Meanwhile, Pirenaica heifers with LL genotype showed negative correlations with 18:3n-3 and total $n-3$ contents in $\operatorname{SCD} 1(p \leq 0.05)$, while these correlations were positive in $\operatorname{SCD} 5(p>0.05)$. The additive SS/SL genotype showed that Pirenaica heifers had positive correlations with $18: 2 n-6, n-6$ and PUFA contents in $S C D 1(p \leq 0.05)$ whereas no statistically significant correlations were observed in $S C D 5$.

In Holstein-Friesian cows (LL genotype only) positive correlation was observed between SCD1 expression and total MUFA content $(p \leq 0.05)$. In comparison, opposite and less significant correlations were observed in SCD5. 


\section{Discussion}

The SREBP1 84 bp-indel polymorphism has been already discovered and genotyped by a conventional PCR amplification and gel electrophoresis [15]. In the present study, the HRM technique was applied, which is a fast, simple and highly reliable method developed from previously established genotyping technologies [37]. An optimized protocol with a new screening method to genotype the insertion/deletion of the polymorphism of interest ( $84 \mathrm{bp}$-indel) by real-time PCR-HRM analysis has been successfully performed (Figure 1).

Transcription regulations of SREBP1 and SREBP2 are preferentially specified for FA and cholesterol metabolism, respectively [38], while gene duplication occurred when independent regulation of FA and cholesterol was required [9]. However, little is known about the subcutaneous fat tissue in bovine and other mammals. The maximum-likelihood mRNA tree of SREBP1 showed a phylogenetic organization (Figure 2) similar to previous studies performed with mitochondrial DNA of ruminants and mammals [39]. Alignments of bovine SREBP1 full-length gene, mRNA, intron 5, and the $84 \mathrm{bp}$-indel sequences might give an insight into the significance of the indel in other species. The SREBP1 full-length gene alignment showed that similarity among mammals in intron 5 was higher than in other introns (Figure 2b). In ruminant mammals, the homology of bovine SREBP1 mRNA coding sequence was lower (85-99\%, Figure 2a) in comparison with the homology of intron 5 (96-99\%, Figure $2 b)$. This result was unexpected since mRNA is normally translated to protein, which is better conserved compared to non-coding introns. Homology between Bos taurus and Bos indicus was the highest (99\%) in all alignments (Figure 2a and 2b). S allele (deletion) seems to be absent in Bos indicus sequences of GenBank which is in agreement with LL genotype observed in Asian zebu breeds [18]. On the other hand, the $84 \mathrm{bp}$-indel region showed the highest homology among ruminants ( $\geq 99 \%$, Figure $2 b$ ), compared to mRNA or intron 5 regions. In non-ruminant mammals, homology was also higher in the 84 bp-indel region (56-76\%) compared with intron $5(45-71 \%)$. And our results also showed higher homology in the 84 bp-indel region compared to full intron 5 (Figure 2b), especially in ruminants, suggesting that this could be a well conserved region throughout evolution with an undetermined functions in SREBP1 or that even could act regulating transcription levels of downstream genes. Similarly, intron 16 of SREBP1 has been described to be highly conserved among mammals [40], which encodes a non-coding RNA (miR-33) in cattle [41]. Accordingly, alignment analyses concluded that $84 \mathrm{bp}$-indel region seems to be highly conserved in mammals. However, the absence of $\mathrm{S}$ allele in mammals other than Bos taurus suggests that the $84 \mathrm{bp}$-indel polymorphism could have appeared after Bos indicus and Bos taurus species differentiation, reported to occur 1.7-2 million years ago [39].

In terms of bovine commercial types studied, Pirenaica is the most important beef cattle breed in northern Spain, highly appreciated for its value as a genetic resource as well as for its production traits. But French Salers cattle and Holstein-Friesian cull cows are also an integral part of the regional beef supply. This study characterized the 84 bp-indel polymorphism of the SREBP1 gene and showed, for the first time, the presence of $S$ allele in Salers and Pirenaica cattle breeds (Table 1). In previous studies with bigger sample size, only SL and LL genotypes were reported in Simmental and crossbred beef breeds [23, 25]. In Salers 
bulls and Pirenaica heifers, the observed frequency of SS and LL genotypes was higher than the expected which could indicate an excess of homozygote individuals, although the Hardy-Weinberg equilibrium did not show significant differences for any of the commercial types studied (Table 1). The frequency of $S$ allele in Salers bulls was 0.385, higher than Pirenaica heifers (0.214) and bulls (0.135). In contrast, all Holstein-Friesian individuals showed LL genotype as already reported [18, 20,21] which could have been the consequence of a high selection pressure towards milk production. The scientific literature shows that beef breeds seem to have higher S allele frequency compared to dairy breeds. Interestingly, S allele frequency of Salers was similar to Limousin $(0.335$; [20]) breed, which might be an effect of the phylogenetically and geographically close relationship between the two breeds [42]. In general, these results indicate higher $S$ allele frequencies in European beef cattle breeds, although the highest frequency values were reported in Japanese Black (0.450; [18]).

This polymorphism has been associated to FA composition. First, Hoashi et al. [15] indicated that S allele of the $84 \mathrm{bp}$-indel contributed to a higher (1.3\%) intramuscular MUFA content in Japanese Black. In terms of individual MUFAs, SL genotype was associated with significantly higher contents of 9c-14:1 compared to LL genotype in subcutaneous fat of Simmental bulls [23], while in intramuscular fat, LL showed higher $9 c-16: 1$ and $9 c-17: 1$ contents than SL genotype of Simmental bulls [27]. In the present study, only Pirenaica bulls showed slightly higher backfat MUFA content in SS/SL compared to LL genotype ( $p>$ 0.05). Bhuiyan et al. [43] reported higher stearic acid (18:0) content in muscle fat of Korean Hanwoo bulls with LL genotype compared to LS and SS genotype. However, in the present study, a higher but not significant 18:0 content was observed in SS/SL compared to LL genotype in all commercial types (Table 2) which was in agreement with the results obtained by Xu et al. [27] in muscle fat of Simmental bulls. In terms of PUFA content, the higher content in $18: 3 n-3$ and total $n-3$ in SS/SL than LL genotype of Pirenaica bulls may suggest an effect of this polymorphism on PUFA content in this commercial type ( $p$ $\leq 0.05$; Table 2), although SS was the highest compared to SL and LL genotypes ( $p>0.05$; data not shown). Only Bhuiyan et al. [43] reported higher muscle 18:2n-6 and total PUFA contents in SS compared to LL genotype. The high correlations between SREBP1 gene expression and UFA contents in Salers bulls (Figure 3), together with their highest $S$ allele frequency compared to other European cattle breeds $(0.385$; Table 1), could indicate a greater influence of $S$ allele in SREBP1 and/or FA content. When all individuals with SS genotype were considered together, positive correlations were observed between gene expression and PUFAs, while negative correlations were observed with the rest of the FAs. Some of these associations could be also explained by the linkage between this DNA marker and other causative polymorphisms [25].

In other studies, associations of rs419112290, located in exon 14 of SREBP1, with fat content and transMUFA of milk in Holstein-Friesian have been found [16], but also with 14:0, 16:0, 9c-18:1, 18:2n-6, 18:3n3 , SFA and MUFA of muscle fat in Asian cattle [26]. Holstein-Friesian cows, with only LL genotype, different correlation patterns in SFAs compared to the other commercial types were observed. The different correlations in Holstein-Friesian cows could be related to a less homogeneous diet and older age of these animals, but also their selection towards milk production compared to Pirenaica and Salers which are specifically raised for meat production.

Page $7 / 20$ 
In previous publications, $S C D$ s have been associated with FA composition of adipose tissues $[16,17,23$, $44,45,46]$. The fact that the $84 \mathrm{bp}$-indel of SREBP1 is associated with FA content would be possible because the downstream genes, such as $S C D S$, could be regulated through the transcriptional regulation. SREBP1 can directly activate the expression of over 30 genes [38]. As expected, several patterns observed between SREBP1 and FAs were also noted in correlations with SCDs (Figure 4). For example, positive correlations observed between SREBP1 and PUFAs in SS genotype of Salers ( $p>0.05$; Figure 3$)$, became significant when SCD1 and PUFA correlations were calculated for same genotype $(p<0.05$; Figure 4$)$. Thus, this might suggest that the regulation through SREBP1 to SCD1 can affect PUFA content in SS genotype of Salers bulls. However, this statement should be carefully considered, since Salers bulls with SS genotype only permits correlation analysis without covariate (SREBP1 gene expression; see statistical analysis section). Interestingly, negative correlations observed between SREBP1 and SFA in LL genotype of Salers ( $p>0.05$; Figure 3$)$, also became significant for SCD1 and SFA correlations $(p<0.05$; Figure 4$)$, indicating a stronger effect of SCD1 than SREBP1 on SFA in LL genotype of Salers. These results are not unexpected since SCD1 desaturates SFA to MUFA and PUFA, and the relationship between SREBP1 and $S C D 1$ in Salers was previously demonstrated [17]. These results indicate that in Salers the effect of SREBP1, and particularly SCD1, on SFA and PUFA seems to be different depending of the 84 bp-indel genotype. However, this assertion could not be corroborated through differences in SFA and PUFA contents reported (Table 2).

On the other hand, the 18:0, 18:3n-3 and total $n-3$ content differences observed between SS/SL and LL genotypes of Pirenaica bulls (Table 2), should be further investigated with a larger sample size of Pirenaica bulls that could increase the $S$ allele frequency to sufficiently evaluate its effect. Nevertheless, significant correlations between SCD1 and SFAs (including 16:0) were observed in SL genotype of Pirenaica bulls, but also $9 c-16: 1$ in Pirenaica breed. In our previous study [17], $9 c-16: 1$ desaturation index was significantly correlated with SCD1 in Pirenaica bulls while these results suggested that relationship between $S C D 1$ and 16:0/9c-16:1 FA contents might be different depending on the indel genotype. Differences between Pirenaica bulls and heifers might occur as a result of a stronger lipogenic gene regulation in a sex dependent manner. In Pirenaica bulls, SS/SL had significantly higher 18:0 content than LL genotype (Table 2) and this higher 18:0 content might indirectly increase the expression of SCD1 giving rise to a positive correlation between $S C D 1$ and $9 c-18: 1$ observed in Pirenaica breed and all individuals (Figure 4). In Pirenaica heifers and all individuals group, SS and SS/SL genotypes showed a positive correlation between SCD5 and 18:0, whereas it was negative between SCD5 and 9c-18:1.

Therefore the relationship between $S C D 5$ and 18:0/9c-18:1 content could also be quite dependent on the indel genotype. Overall, the content of several SFAs and corresponding UFAs (i.e., 16:0/9c-16:1 and 18:0/9c-18:1) are related as a result of the unsaturation by $S C D 1$ or $S C D 5$. Moreover, opposite correlations between these lipogenic genes with 16:0 and $9 c-16: 1$, but also 18:0 and $9 c-18: 1$, seems to be dependent on the indel genotype, especially in Pirenaica breed. Indeed, in Pirenaica, it might be more evident the transcriptional feedback regulation of SREBP-SCAP-INSIG complex, where SREBP1 promotes the desaturation of SFA into UFAs by SCDs. Whereas, UFAs stabilize INSIG1 protein which acts as an inhibitor of SREBP1 activity by retaining the inactive SREBP/SCAP complex in the ER membrane [6]. Consequently, 
expression of SREBP1 produces a negative feedback regulation, influencing its own activity and SCD desaturation. In a previous study, we reported a novel genetic compensation mechanism between SCD1 and $S C D 5$ that showed that one $S C D$ isoform could well be compensated by upregulation the other isoform [17]. This opposite pattern has been consistently detected even when individuals were separated by the $84 \mathrm{bp}$-indel. Thus, this mechanism might strongly regulate expression of both $S C D S$, although the pathway by which it occurs remains unclear. Several transcription factors apart from SREBP1 such as $\angle X R, P P A R a, C / E B P a, N F-1, N F-Y$, and $S p 1$, have also been revealed to bind to the SCD1 promoter region [47]. It has been proposed that $S C D 1$ is mainly regulated by a wide variety of hormones and nutrients, while $S C D 5$ is not affected by external inputs like food sources [48]. Discrepancies of $S C D 5$ regulation among species and tissues showed a SREBP1 binding site only in human SCD5 but not in other mammals [49], while other studies support a direct regulation of $S C D 5$ by SREBP1 in skeletal muscle cells [50] or even directly binding to the promoter of SCD5 in cattle [51]. Further studies are necessary to establish the mechanism by which both $S C D$ isoforms are compensated and clarify their regulation by $S R E B P 1$ in beef (muscle and fat), leading to meat production with favorable characteristics.

\section{Conclusions}

The phylogenetic analysis has demonstrated the high homology in the $84 \mathrm{bp}$-indel and flanking regions suggesting the need for its conservation throughout evolution in ruminants. Therefore, the $84 \mathrm{bp}$-indel sequence may have an undetermined function in SREBP1 or may even act regulating transcription levels of downstream genes, although the molecular mechanism through which influences FA content remains uncertain. Controlled studies will help to elucidate the effect of $84 \mathrm{bp}$-indel along with lipogenic gene regulation and FA composition. Our results suggest that the $84 \mathrm{bp}$-indel polymorphism is associated with FA composition and lipogenic gene expression among commercial types of beef cattle in Basque country. The 84 bp-indel has been related to FA composition, especially in Pirenaica bulls which SS/SL genotype was associated with higher SFA and PUFA contents. Gene expression of SREBP1 seems to be differently correlated with UFA contents depending on the indel genotype and commercial types, since SS genotype showed different correlations in Pirenaica heifers and Salers. Moreover, several differences were observed in correlations between $S C D$ s and FAs depending on the indel, while the compensation pattern between $S C D 1$ and $S C D 5$ was maintained even when commercial types were separately evaluated by the indel.

\section{Methods}

\section{Sample collection}

Bovine commercial types typically destined to meat production in northern Spain (Basque region) were used. Description of commercial types and sample collection details were previously given [17, 28]. Briefly, subcutaneous adipose tissue samples from the $5-6^{\text {th }}$ rib and neck (sternomandibularis) muscle samples were collected from the left half carcasses of purebred cattle (13 Salers bulls, 37 Pirenaica bulls, 28 Pirenaica heifers, and 21 Holstein-Friesian cows; $n=99)$. Both, backfat for FA analysis and neck 
muscle samples for genotyping were stored in separated plastic bags with the air removed. Whereas, backfat samples for RNA analysis were preserved in RNAlater ${ }^{\text {TM }}$ (Ambion, Austin, TX). All samples were transported to the laboratory in insulated coolers and stored at $-80^{\circ} \mathrm{C}$ until analysis.

\section{Analysis of fatty acid composition}

The FA analysis was previously described in Gamarra et al. [17]. Briefly, a $50 \mathrm{mg}$ sample of backfat was directly derivatized with sodium methoxide [29] and for quantitation purposes internal standard (23:0 methyl ester) was added prior to derivatization. Resulting FA methyl esters were analyzed by gas chromatography with flame ionization detection using two complementary 100 m columns; SP-2560 [30] and SLB-IL111 [31]. FA data were reported in $\mathrm{mg} / \mathrm{g}$ of fat.

\section{Genotyping of bovine SREBP1}

DNA was extracted from $5 \mathrm{mg}$ of neck muscle tissue with Proteinase-k and single lysis-salting out method. DNA samples were quantified with a NanoDrop ND-1000 spectrophotometer (Thermo Scientific, Wilmington, DE, USA) and diluted to $50 \mathrm{ng} / \mu \mathrm{L}$. First, SREPB1 $84 \mathrm{bp}$-indel was detected by simple sequence length polymorphism (SSLP) of PCR amplicons. The PCR amplifications for SREBP1 were carried out in a final volume of $25 \mu \mathrm{L}$ containing $1 \mathrm{U}$ of KOD-plus DNA polymerase (TOYOBO, Osaka, Japan), $2.5 \mu \mathrm{L}$ of 10X PCR buffer, $2.5 \mathrm{mM} \mathrm{MgSO}_{4}, 25-50 \mathrm{ng}$ of genomic DNA, $2 \mathrm{mM}$ dNTP (Takara Biotechnology Co, Ltd, Shiga, Japan), and $10 \mu \mathrm{mol}$ of each primer. Primers used were F: 5'TGACCTCCCAGATACAGCAG-3' and R: 5'-GCTACTCAACAGCAGGATCTC-3'. Amplification conditions were $94^{\circ} \mathrm{C}$ for $2 \mathrm{~min}, 30$ cycles of $94^{\circ} \mathrm{C}$ for $5 \mathrm{~s}, 60^{\circ} \mathrm{C}$ for $15 \mathrm{~s}, 68^{\circ} \mathrm{C}$ for $1.5 \mathrm{~min}$, and a final extension at $72^{\circ} \mathrm{C}$ for $10 \mathrm{~min}$. Amplification products were subjected to electrophoresis on $1.5 \%$ agarose gels and visualized with GelRed (Biotium Inc., Hayward, USA) and UV light. The individuals were genotyped according to the length of PCR products. Then, real-time PCR and high resolution melting (HRM) were optimized to genotype the 84 bp-indel polymorphism. CFX-96 Real-Time System (Bio-Rad Laboratories, California, USA) and following primers (5'-AGAAACGCTACCGCTCTTCC-3' and 5'-

GCTACTCAACAGCAGGATCTC-3'), $0.75 \mu \mathrm{M}$ of each universal primer, $2.5 \mu \mathrm{L}$ of SsoFast ${ }^{\mathrm{TM}}$ EvaGreen ${ }^{\circledR}$ supermix and $1 \mu \mathrm{L}$ of DNA template $(1 \mathrm{ng} / \mu \mathrm{L})$ were used. PCR and HRM were performed following an initial denaturation at $98^{\circ} \mathrm{C}$ for $2 \mathrm{~min} ; 40$ cycles at $98^{\circ} \mathrm{C}$ for $5 \mathrm{~s}$, and $50^{\circ} \mathrm{C}$ for $30 \mathrm{~s}$ [32]. Plate reads were taken after the initial step of $95^{\circ} \mathrm{C}$ for $30 \mathrm{~s}$ and $60^{\circ} \mathrm{C}$ for $2 \mathrm{~min}$, and the melting curve went from $65^{\circ} \mathrm{C}$ to $95^{\circ} \mathrm{C}$ with an increment of $0.5^{\circ} \mathrm{C}$ every $5 \mathrm{~s}$.

\section{Gene expression analysis of bovine lipogenic genes}

Total RNA was extracted using RNeasy Lipid Tissue kit (Qiagen Inc., Valencia, CA, USA) and analyzed with Custom TaqMan Assay (Applied Biosystems, Foster City, CA, USA) to measure the relative expression 
level of SREBP1 and SCD isoforms (SCD1 and SCD5)following the conditions and details reported in Gamarra et al. [17]. Reverse transcription was performed using ReverTra Ace reverse transcriptase (TOYOBO, Osaka, Japan), while Real time PCR was conducted to measure the relative expression levels of each candidate gene in multiplex with an internal control (18S rRNA Endogenous Control VIC/TAMRA Probe, Primer Limited) by the co-application of reverse transcription method (Co-RT). Real-time PCR was performed in triplicate using the ABI Prism 7500 Sequence Detection System (Applied Biosystems, Foster City, CA, USA) and PCR efficiency was calculated per sample and amplicons using LinRegPCR (Heart Failure Research Center, Amsterdam, the Netherlands). Efficiencies were over $90 \%$ for all samples and correlation coefficients were over 0.99 . The comparative threshold cycle method $(\Delta \mathrm{Ct})$ was employed to calculate the relative gene expression based on this formula: $\Delta \mathrm{Ct}=\left(\mathrm{Ct}_{\text {target gene }}-\mathrm{Ct}_{18 \mathrm{~S} \text { rRNA gene }}\right)$.

\section{Statistical analysis}

Genotype and allele frequencies of SREBP1 variants were estimated and Chi-squared test $\left(\chi^{2}\right)$ was performed to check whether the populations were in Hardy-Weinberg equilibrium using Genepop 4.2 [33] with a probability test using a Markov chain (dememorization 10000, batches 5000 , iterations per batch 5000).

For the phylogenetic analysis, alignments of SREBP1 mRNA sequences among several ruminants (cattle, zebu, buffalo, sheep, goat) and other mammals (horse, pig, dog, mouse, rat, chimpanzee, human) were made with Muscle algorithm [34]. The data used for sequence alignments were obtained from NCBI's Genbank [35] (accession numbers reported in Supplemental Table 1). Phylogenetic tree inferred from the concatenated alignment of SREBP1 mRNA sequences was constructed using the maximum likelihood method (100 bootstrap) in Unipro Unigene 1.31 [36]. Alignments of the $84 \mathrm{bp}$-indel from bovine SREBP1 and homologous introns of aforementioned mammals were also computed. Homology percentages were calculated based on nucleotide similarity among sequences.

To study SREBP1 genotype and FA associations, IBM SPSS Statistics 22 for Windows was used (SPSS Inc., IBM Corporation, NY, USA). First of all, data was checked for normality and homoscedasticity. Then, the following general linear model was used for analysis of variance (ANOVA): $\mathrm{y}_{i j k}=\mu+I P_{i}+G E_{j}+e_{i j k}$

where $\mathrm{y}_{i j k}=$ dependent variables (FAMEs); $\mu$ = mean value; $I P_{i}=$ effect of 84 bp-indel polymorphism of SREBP1 (SS: Small type with 84 bp deletion; LL: Long type with 84 bp insertion; SL: Heterozygote with 84 bp deletion and insertion); $G E_{j}=$ covariate, gene expression of SREBP1 $(\triangle \mathrm{Ct}) ; e_{i j k}=$ random residual effect. Even though initially the additive model (SS, SL and LL) was evaluated, the recessive model (SS/SL and LL) was finally selected as a more explanatory. Least significant difference (LSD) post hoc test was applied for multiple comparison of means among genotypes studied considering 84 bp-indel frequencies.

Pearson correlations were computed among gene expression $(\triangle \mathrm{Ct})$ of $S R E B P 1$, considering the $84 \mathrm{bp}$ indel, and main individual and FA groups (SFA, 16:0, 18:0, MUFA, $9 c-16: 1,9 c-18: 1$, PUFA, $n-6,18: 2 n-6, n-$ 
3 , and $18: 3 n-3)$ to evaluate differences among commercial types.

In addition, partial Pearson correlations adjusted for GE were computed, whenever it was permitted by sample size, between gene expression of downstream genes (SCD1 and SCD5) and main individual and FA groups considering the $84 \mathrm{bp}$-indel genotypes, since it represented more accurately the effects of SREBP1-indel on SCD1/5 genes and FAs. Heatmap matrix for the effect of genotypes (SS, SL, SS/SL and $\mathrm{LL})$ on the partial correlations between each gene expression $(\Delta \mathrm{Ct})$ and FA content $(\mathrm{mg} / \mathrm{g}$ fat) was represented. Significance was declared at $p \leq 0.05$.

\section{Abbreviations}

bp: base pair; c: Cis; FA: Fatty acid; MUFA: Monounsaturated fatty acids; PUFA: Polyunsaturated fatty acids; SCD: Stearoyl-CoA desaturase; SFA: Saturated fatty acids; SREBP: Sterol regulatory elementbinding protein; $t$ : Trans; UFA: Unsaturated fatty acids

\section{Declarations}

\section{Ethics approval}

All animals were handled at slaughterhouse following the European Council Regulation (EC) $\mathrm{N}^{\circ}$ 1099/2009. All material was sampled after slaughter and therefore do not require any ethical consideration or approval.

\section{Availability of data and materials}

The datasets used and/or analyzed during the current study are available from the corresponding authors on reasonable request.

\section{Competing interests}

\section{The authors declare that they have no competing interests.}

\section{Funding}

Department of Economic Development \& Competitiveness of the Basque Government supported the doctoral fellowship of D. G. This study was funded by the Basque Government (Grupo Consolidado IT833-13 Biomics \& IT944-16 Lactiker).

\section{Authors' contributions}


DG analyzed all experimental data used in this study and drafted the manuscript. NA analyzed and interpreted fatty acid composition data. AA participated in statistical analyses. MT analyzed and interpreted lipogenic gene expression data. MMP participated in the interpretation and discussion of data. All authors contributed to the writing of the manuscript and gave final approval for its publication.

\section{Acknowledgements}

Help and advice provided by Dr. Mikawa is very much appreciated. Technical support provided by SGlker (DNA Bank Service of UPV/EHU) and abattoir staff from Arakai-Urkaiko is also acknowledged.

\section{References}

1. Burlingame B, Nishida $C$, Uauy R, Weisell R. Fats and fatty acids in human nutrition. Joint FAO/WHO expert consultation. Ann Nutr Metab. 2009;55:5-7.

2. Vannice G, Rasmussen H. Position of the academy of nutrition and dietetics: Dietary fatty acids for healthy adults. J. Acad. Nutr. Diet. 2014;114:136-153.

3. Brooks MA, Choi CW, Lunt DK, Kawachi H, Smith SB. Subcutaneous and intramuscular adipose tissue stearoyl-coenzyme a desaturase gene expression and fatty acid composition in calf- and yearling-fed Angus steers. J Anim Sci. 2011;89:2556-70.

4. Brown MS, Goldstein JL. The SREBP pathway: regulation of cholesterol metabolism by proteolysis of a membrane-bound transcription factor. Cell. 1997;89:331-40.

5. Horton JD, Shimomura I, Brown MS, Hammer RE, Goldstein JL. Activation of cholesterol synthesis in preference to fatty acid synthesis in liver and adipose tissue of transgenic mice overproducing sterol regulatory element-binding protein-2. J. Clin. Invest. 1998;101:2331-2339

6. Eberlé D, Hegarty B, Bossard P, Ferré P, Foufelle F. SREBP transcription factors: master regulators of lipid homeostasis. Biochimie 2004; 86: 839-848. \

7. Shimomura I, Shimano H, Horton JD, Goldstein JL, Brown MS. Differential expression of exons 1a and $1 \mathrm{c}$ in mRNAs for sterol regulatory element binding protein-1 in human and mouse organs and cultured cells. J Clin Invest. 1997;99:838-45.

8. Zimin AV, Delcher AL, Florea L, Kelley DR, Schatz MC, Puiu D, Hanrahan F, Pertea G, Van Tassell CP, Sonstegard TS, Marçais G, Roberts M, Subramanian P, Yorke JA, Salzberg SL. A whole-genome assembly of the domestic cow, Bos taurus. Genome Biol. 2009;10:R42.

9. Osborne TF, Espenshade PJ. Evolutionary conservation and adaptation in the mechanism that regulates SREBP action: what a long, strange tRIP it's been. Genes Dev. 2009;23:2578-91.

10. Bao J, Zhu L, Zhu Q, Su J, Liu M, Huang W. SREBP-1 is an independent prognostic marker and promotes invasion and migration in breast cancer. Oncol Lett. 2016;12:2409-2416.

11. Picard C, Julien C, Frappier J, Miron J, Theroux L, Dea D, et al 2018 Alterations in cholesterol metabolism-related genes in sporadic Alzheimer's disease. Neurobiol Aging 2018;66:180. 
12. Bauman DE, Harvatine KJ, Lock AL. Nutrigenomics, rumen-derived bioactive fatty acids, and the regulation of milk fat synthesis. Annu Rev Nutr. 2011;31:299-319.

13. Ladeira MM, Schoonmaker JP, Gionbelli MP, Dias JC, Gionbelli TR, Carvalho JR, Teixeira PD. Nutrigenomics and Beef Quality: A Review about Lipogenesis. Int J Mol Sci. 2016;17.

14. Shimano H. Sterol regulatory element-binding proteins (SREBPs): transcriptional regulators of lipid synthetic genes. Prog Lipid Res. 2001;40:439-52.

15. Hoashi S, Ashida N, Ohsaki H, Utsugi T, Sasazaki S, Taniguchi M, Oyama K, Mukai F, Mannen H. Genotype of bovine sterol regulatory element binding protein-1 (SREBP-1) is associated with fatty acid composition in Japanese black cattle. Mamm Genome. 2007;18:880-6.

16. Rincon G, Islas-Trejo A, Castillo AR, Bauman DE, German BJ, Medrano JF. Polymorphisms in genes in the SREBP1 signalling pathway and SCD are associated with milk fatty acid composition in Holstein cattle. J Dairy Res. 2012;79:66-75. 区

17. Gamarra D, Aldai N, Arakawa A, Barron LJR, Lopez-Oceja A, de Pancorbo MM, Taniguchi M. Distinct correlations between lipogenic gene expression and fatty acid composition of subcutaneous fat among cattle breeds. BMC Vet Res. 2018;14:167.

18. Kaneda M, Lin BZ, Sasazaki S, Oyama K, Mannen $H$. Allele frequencies of gene polymorphisms related to economic traits in Bos taurus and Bos indicus cattle breeds. Anim Sci J. 2011;82: 717-21.

19. Öztabak KÖ, Akad IA, Gürsel FE, Ate A, Yardibi H, HOtürk GT. Indel mutation of the ADD1/SREBP-1C gene in the South Anatolian Red and East Anatolian Red cattle breeds. Turk J Vet Anim Sci. 2013;37:255-58.

20. Proskura WS. Insertion/deletion polymorphism of the sterol regulatory element-binding protein 1 gene in different cattle breeds. Turk J Vet Anim Sci. 2014;38:104-06.

21. Huang YZ, Zhang EP, Wang J, Huai YT, Ma L, Chen FY, Lan XY, Lei CZ, Fang XT, Wang JQ, Chen H. A large indel mutation of the bovine ADD1/SREBP1c gene and its effects on growth traits in some native cattle breeds from China. Mol Biol Rep. 2011;38:2037-42.

22. Proskura W, Dybus A, Zaborski D, SOBEK Z, Yu Y, Cheng Y. Polymorphism in the SREBP-1 gene is associated with milk production traits of Jersey cattle Indian J Anim Sci. 2017; 87:924-926.

23. Barton L, Kott T, Bures D, Rehák D, Zahrádková R, Kottová $B$. The polymorphisms of stearoyl-CoA desaturase (SCD1) and sterol regulatory element binding protein-1 (SREBP-1) genes and their association with the fatty acid profile of muscle and subcutaneous fat in Fleckvieh bulls. Meat Sci. 2010;85:15-20.

24. Matsuhashi T, Maruyama S, Uemoto Y, Kobayashi N, Mannen H, Abe T, Sakaguchi S, Kobayashi E. 2011. Effects of bovine fatty acid synthase, stearoyl-coenzyme A desaturase, sterol regulatory element-binding protein 1 , and growth hormone gene polymorphisms on fatty acid composition and carcass traits in Japanese Black cattle. J Anim Sci. 2011;89:12-22. 
25. Han C, Vinsky M, Aldai N, Dugan ME, McAllister TA, Li C. Association analyses of DNA polymorphisms in bovine SREBP-1, LXRa, FADS1 genes with fatty acid composition in Canadian commercial crossbred beef steers. Meat Sci. 2013;93:429-36.

26. Lee Y, Oh D, Lee J, La B, Yeo J. Novel single nucleotide polymorphisms of bovine SREBP1 gene is association with fatty acid composition and marbling score in commercial Korean cattle (Hanwoo). Mol Biol Rep. 2013;40:247-54.

27. Xu L, Zhang LP, Yuan ZR, Guo LP, Zhu M, Gao X, Gao HJ, Li JY, Xu SZ. Polymorphism of SREBP1 is associated with beef fatty acid composition in Simmental bulls. Genet Mol Res. 2013;12:5802-9.

28. Aurtenetxe M, Belaunzaran X, Bravo-Lamas L, Gamarra D, Barron LJR, Aldai N. Caracterización comercial y nutricional de la grasa subcutánea de terneros y vacas de desvieje sacrificados en la Comunidad Autónoma del País Vasco. Archivos de Zootecnia. 2017;66:435-42.

29. Kramer JK, Fellner V, Dugan ME, Sauer FD, Mossoba MM, Yurawecz MP. Evaluating acid and base catalysts in the methylation of milk and rumen fatty acids with special emphasis on conjugated dienes and total trans fatty acids. Lipids. 1997;32:1219-28.

30. Kramer JK, Hernandez M, Cruz-Hernandez C, Kraft J, Dugan ME. Combining results of two GC separations partly achieves except CLA isomers of milk fat as demonstrated using ag-ion SPE fractionation. Lipids. 2008;43:259-73.

31. Delmonte P, Fardin-Kia AR, Kramer JKG, Mossoba MM, Sidisky L, Tyburczy C, Rader JI. Evaluation of highly polar ionic liquid gas chromatographic column for the determination of the fatty acids in milk fat. J Chromatogr A. 2012;1233:137-46.

32. Lopez-Oceja A, Nuñez C, Baeta M, Gamarra D, de Pancorbo MM. Species identification in meat products: A new screening method based on high resolution melting analysis of cyt $b$ gene. Food Chem. 2017;237:701-706.

33. Raymond M, Rousset F. GENEPOP Version 1.2: Population genetics software for exat tests and ecumenicism. J Heredity. 1995:248-249.

34. Edgar RC. MUSCLE: multiple sequence alignment with high accuracy and high throughput. Nucleic Acids Res. 2004;32:1792-7.

35. Benson DA, Cavanaugh M, Clark K, Karsch-Mizrachi I, Lipman DJ, Ostell J, Sayers EW. GenBank. Nucleic Acids Res. 2017;45:37-42.

36. Okonechnikov K, Golosova O, Fursov M. the UGENE team. Unipro UGENE: a unified bioinformatics toolkit. Bioinformatics. 2012;28:1166-1167.

37. Liew M, Pryor R, Palais R, Meadows C, Erali M, Lyon E, Wittwer C. Genotyping of single-nucleotide polymorphisms by high-resolution melting of small amplicons. Clin Chem. 2004;50:1156-64.

38. Horton JD, Goldstein JL, Brown MS. SREBPs: activators of the complete program of cholesterol and fatty acid synthesis in the liver. J Clin Invest. 2002;109:1125-31. \

39. Hiendleder S, Lewalski H, Janke A. Complete mitochondrial genomes of Bos taurus and Bos indicus provide new insights into intra-species variation, taxonomy and domestication. Cytogenet Genome Res. 2008;120:150-6. 
40. Taniguchi M, Nakajima I, Chikuni K, Kojima M, Awata T, Mikawa S. MicroRNA-33b downregulates the differentiation and development of porcine preadipocytes. Mol Biol Rep. 2014;41:1081-90.

41. Strozzi F, Mazza R, Malinverni R, Williams JL. Annotation of 390 bovine miRNA genes by sequence similarity with other species. Anim Genet. 2009;40:125.

42. Gamarra D, Lopez-Oceja A, de Pancorbo M. Genetic characterization and founder effect analysis of recently introduced Salers cattle breed population. Animal. 2017;11:24-32.

43. Bhuiyan MSA, Yu SL, Jeon JT, Yoon D, Cho YM, Park EW, Kim NK, Kim KS, Lee『 JH. DNA Polymorphisms in SREBF1 and FASN Genes Affect Fatty Acid Composition in Korean Cattle (Hanwoo). Asian-Aust. J. Anim. Sci. 2009;6:765-773.

44. Taniguchi M, Utsugi T, Oyama K, Mannen H, Kobayashi M, Tanabe Y, Ogino A, Tsuji S. Genotype of stearoyl-coA desaturase is associated with fatty acid composition in Japanese Black cattle. Mamm Genome. 2004;15:142-8.

45. Kgwatalala PM, Ibeagha-Awemu EM, Hayes JF, Zhao X. Single nucleotide polymorphisms in the open reading frame of the stearoyl-CoA desaturase gene and resulting genetic variants in Canadian Holstein and Jersey cows. DNA Seq. 2007;18:357-62.

46. Li C, Aldai N, Vinsky M, Dugan ME, McAllister TA. Association analyses of single nucleotide polymorphisms in bovine stearoyl-CoA desaturase and fatty acid synthase genes with fatty acid composition in commercial cross-bred beef steers. Anim Genet. 2012;43:93-7.

47. Mauvoisin D, Mounier, C. Hormonal and nutritional regulation of SCD1 gene expression. Biochimie. 2011;93:78-86.

48. Castro LFC, Wilson JM, Gonc \alves O, Galante-Oliveira S, Rocha E, Cunha I. The evolutionary history of the stearoyl-CoA desaturase gene family in vertebrates. BMC Evol Biol. 2011;11:132.

49. Wu X, Zou X, Chang Q, Zhang Y, Li Y, Zhang L, Huang J, Liang B. The evolutionary pattern and the regulation of stearoyl-CoA desaturase genes. Biomed Res Int. 2013;2013:856521.

50. Sinner DI, Kim GJ, Henderson GC, Igal RA. StearoylCoA desaturase-5: a novel regulator of neuronal cell proliferation and diferentiation, PLoS One. 2012;7:e39787.

51. Lengi AJ, Corl BA. Regulation of the bovine SCD 5 promoter by EGR2 and SREBP1. Biochem Biophys Res Commun. 2012;421:375-9.

\section{Tables}

Due to technical limitations, tables are only available as a download in the supplemental files section

\section{Figures}



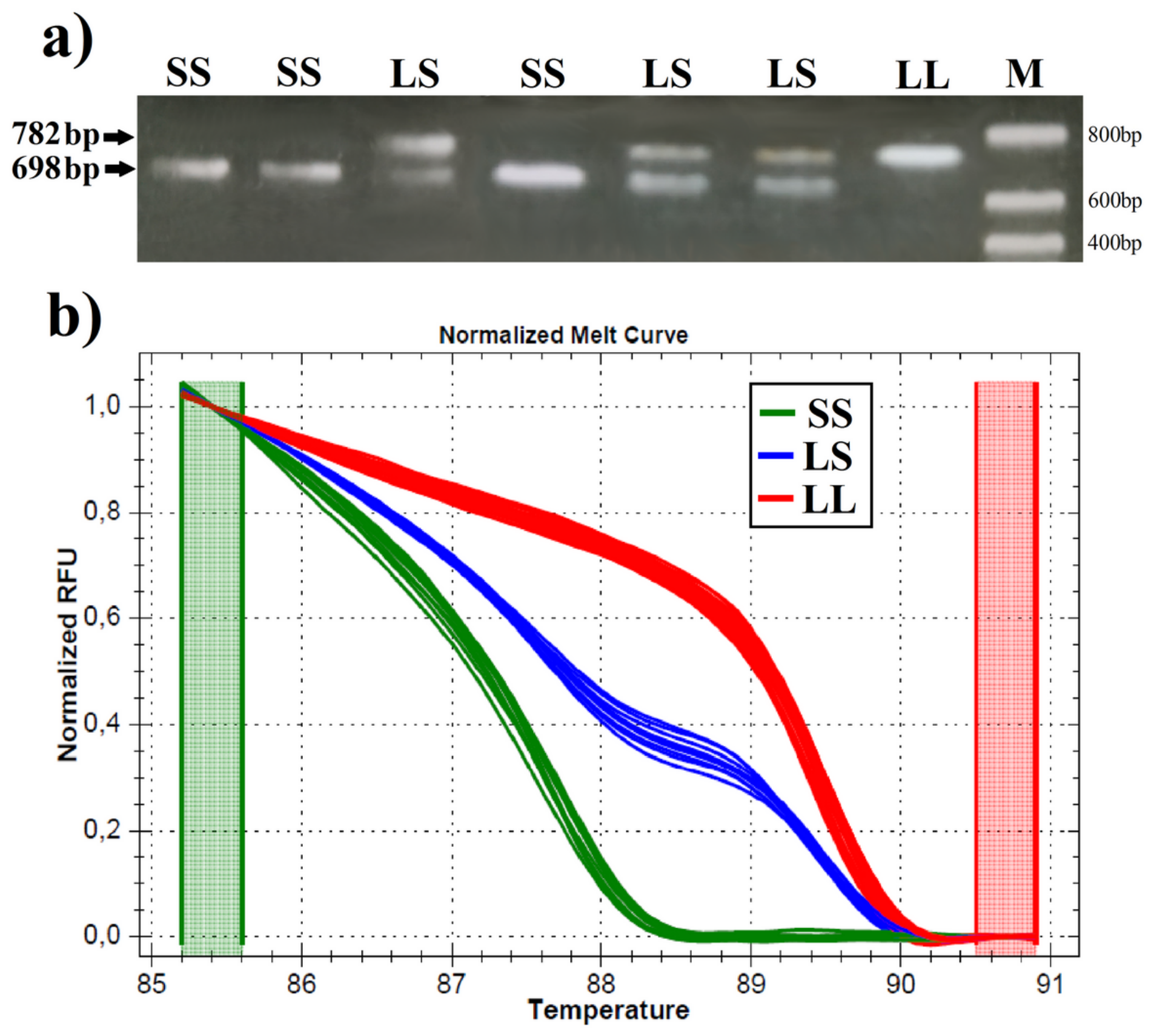

Figure 1

a) Electrophoretic patterns of the DNA region containing the indel ( $1.5 \%$ agarose gel) and b) normalized melting curves showing different 84bp-indel genotypes (HRM) of bovine SREBP1 gene. M: marker, SS: Small homozygote, LS: Long-Small heterozygote, LL: Long homozygote. 
a)

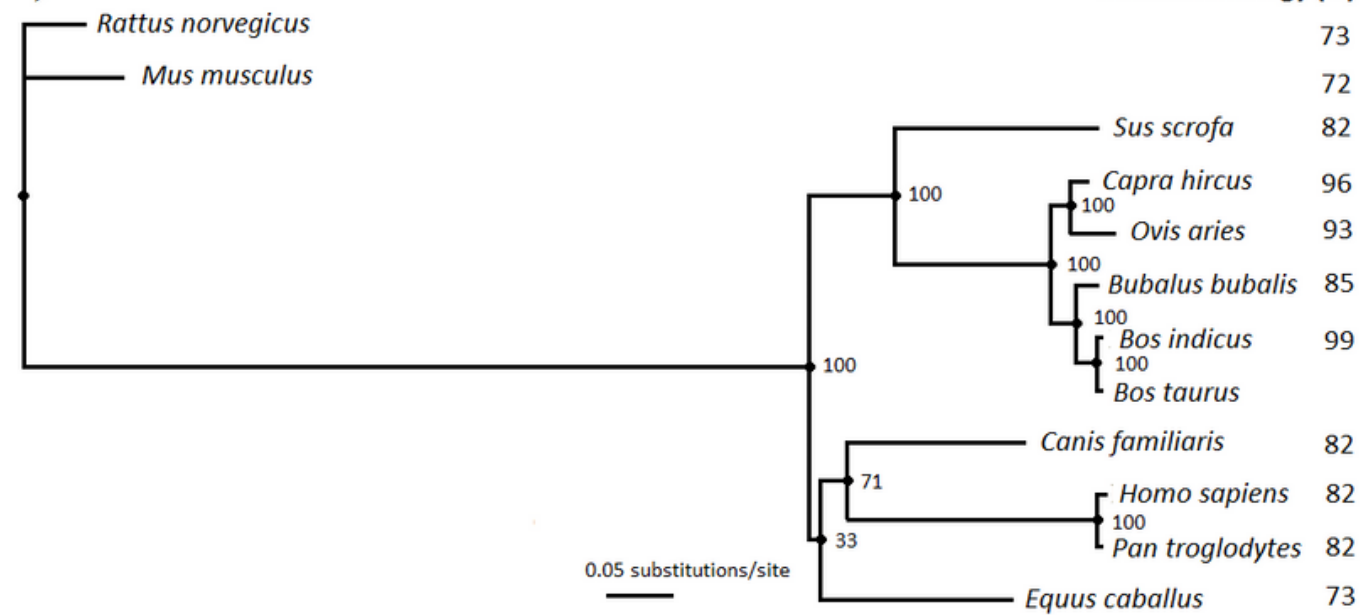

b)

SREBPI gene

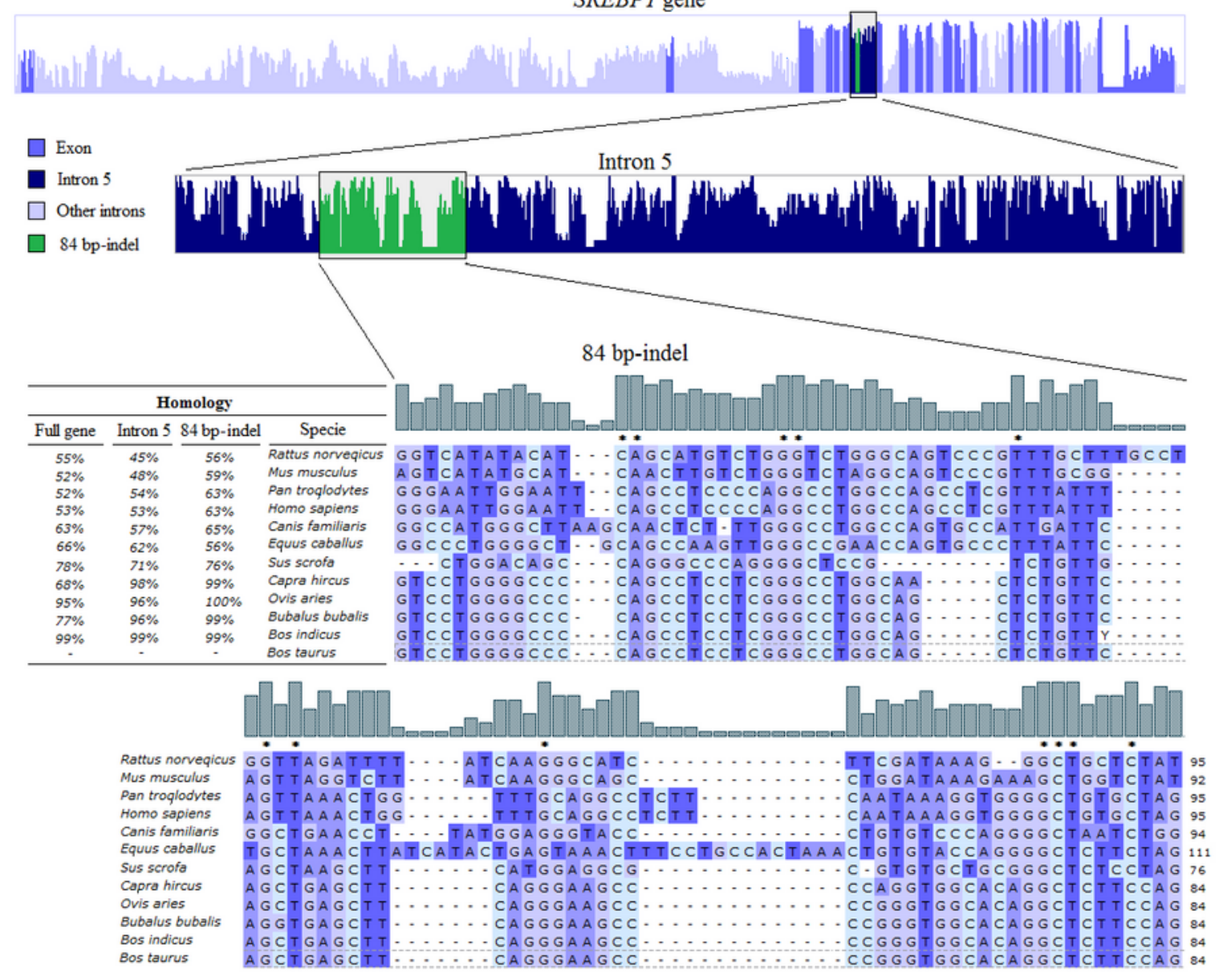

Figure 2

Representation of the (a) maximum-likelihood tree using mRNA of SREBP1 in different mammals (the length of branches represents the expected number of substitutions per site) and the percentage of bootstrap replicates (up to 100) that support each node, and the (b) alignment of bovine genomic sequence of SREBP1, intron 5 and 84 bp-indel region along with homologous sequences of different mammals. 


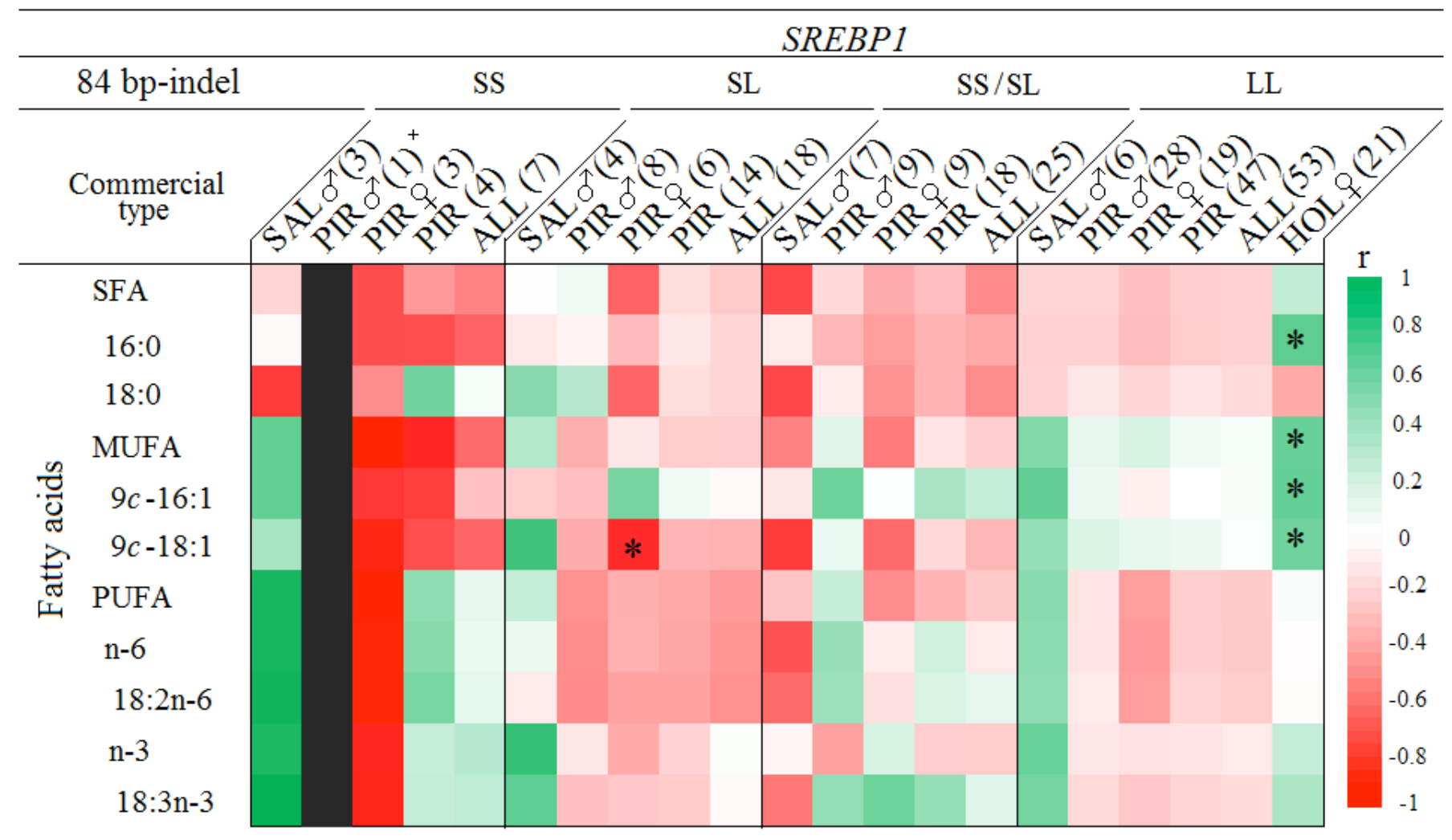

Figure 3

Heatmap matrix of the effect of genotype (SS vs SL vs SS/SL vs LL) on the gene expression of SREBP1 and fatty acid content correlations of subcutaneous adipose tissue of bovine commercial types. SAL区: Salers bulls; PIR囚: Pirenaica bulls; PIR囚: Pirenaica heifers; PIR: Pirenaica bulls \& heifers; ALL: All individuals (Salers \& Pirenaica); HOL囚: Holstein-Friesian cows. Sample size in brackets. + Correlation analysis performed without GE covariate (SREBP1 gene expression) $(n \leq 3)$

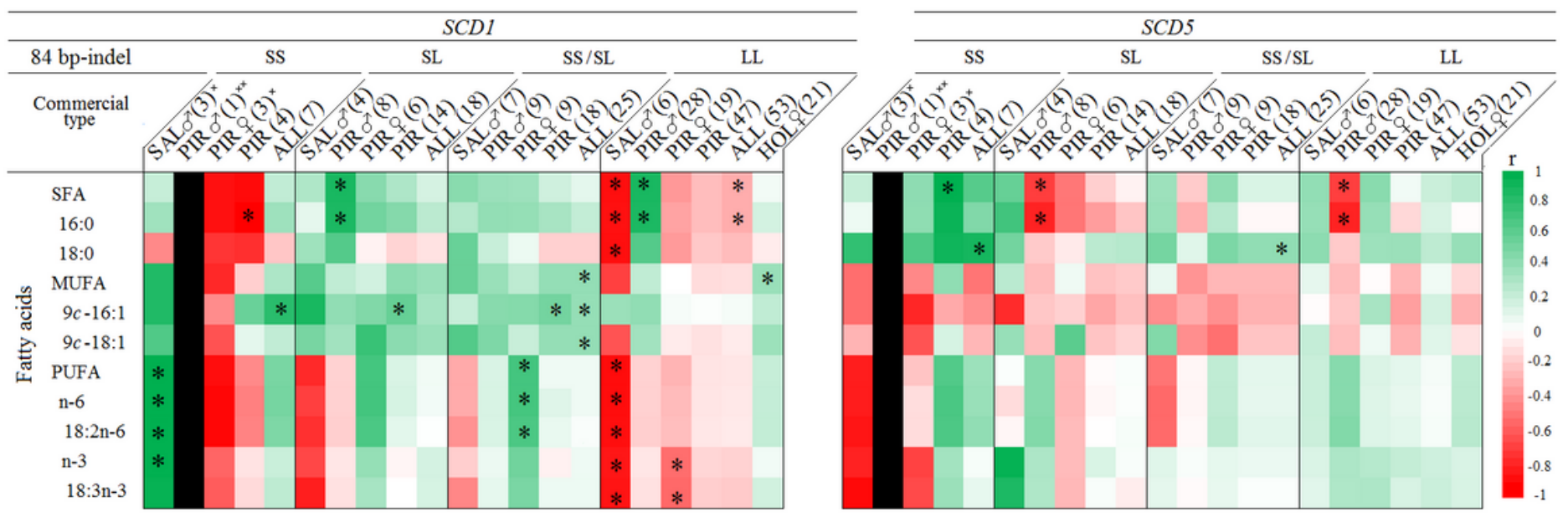

Figure 4 
Heatmap matrix of the effect of genotype (SS vs SL vs SS/SL vs LL) on the gene expression of SCDs (SCD1 and SCD5) and fatty acid content correlations of subcutaneous adipose tissue of bovine commercial types. SAL囚: Salers bulls; PIR囚: Pirenaica bulls; PIR囚: Pirenaica heifers; PIR: Pirenaica bulls \& heifers; ALL: All individuals (Salers \& Pirenaica); HOL®: Holstein-Friesian cows. Sample size in brackets. + Correlation analysis performed without GE covariate (SREBP1 gene expression) $(n \leq 3) ;++$ No correlation analysis performed $(n<2)$.

\section{Supplementary Files}

This is a list of supplementary files associated with this preprint. Click to download.

- Table2.docx

- SupplementalTable1.docx

- Table1.docx 